\title{
TRATAMENTO DE LIXIVIADO DE ATERRO DE CURTUME ATRAVÉS DO PROCESSO DE AIR STRIPPING
}

\section{B. RUBLESKE${ }^{1}$, A. V. de QUADROS ${ }^{2}$, A. M. BERNARDES ${ }^{2}$, M.A.S. RODRIGUES ${ }^{2}$, M. G. SOARES ${ }^{1}$}

${ }^{1}$ Universidade Federal do Rio Grande do Sul (UFRGS), Programa de Pós-graduação em Engenharia

Química, Laboratório de Estudos em Couro e Meio Ambiente (LACOURO).

${ }^{2}$ Universidade Federal do Rio Grande do Sul (UFRGS), Programa de Pós-graduação em

Engenharia de Minas, Metalúrgica e de Materiais (PPGE3M). Rua Eng. Luiz Englert, s/n.

CEP 90040-040 - Porto Alegre - RS, Brasil, Telefone: 55-51-33083954, Fax: 55-5133083277.

E-mail para contato: mbassani@enq.ufrgs.br

\begin{abstract}
RESUMO - Esta pesquisa propõe a remoção da amônia presente no lixiviado por meio do processo físico-químico air stripping, que promove a transferência da amônia da fase líquida para gasosa. Para que não se contribua com a poluição atmosférica, o efluente gasoso do air stripping deve ser tratado em solução de ácido sulfúrico ou água. A neutralização da amônia com solução de ácido sulfúrico gera o sulfato de amônio. Esse subproduto pode ser usado como fertilizante. Com vistas à identificação das condições ótimas de operação do sistema, os testes iniciais foram realizados com solução sintética de 1000 ppm de hidróxido de amônio. Nesta pesquisa, para remoção da amônia do lixiviado (cerca de $27000,00 \mathrm{mg} / \mathrm{L} \mathrm{NH}_{3}$ ), utilizou-se uma torre de acrílico, com $70 \mathrm{~cm}$ de altura e $5 \mathrm{~cm}$ de diâmetro, recheada com anéis do tipo Raschig de polietileno corrugados, com diâmetro de $2,5 \mathrm{~cm}$ e $2 \mathrm{~cm}$ de comprimento. A vazão de ar utilizada foi 10 NL $\min ^{-1}$ e as vazões de lixiviado foram $30 \mathrm{~mL} \mathrm{~min}^{-1}, 175 \mathrm{~mL} \mathrm{~min}^{-1}$ e $350 \mathrm{~mL}$ $\mathrm{min}^{-1}$, sendo que fluxos de líquido e ar eram em contracorrente. Para o recolhimento da amônia foram usados três erlenmeyers de $500 \mathrm{~mL}$, preenchidos com $500 \mathrm{~mL}$ de solução de ácido sulfúrico $0,4 \mathrm{~mol} \mathrm{~L}^{-1}$. Os resultados obtidos nos testes preliminares com solução sintética variaram de 75 a $88 \%$ de eficiência de remoção. A eficiência obtida com lixiviado ficou em $43 \%$ com tempo de ciclo de 24 horas.
\end{abstract}

\section{INTRODUÇÃO}

O impacto ambiental pelo lançamento da amônia na atmosfera é um dos maiores problemas da aplicação do air stripping, pois como se sabe, essa substância é tóxica ao ambiente, especialmente aos recursos hídricos e também ao homem.

Uma das formas viáveis da recuperação (ou retenção) da amônia é passar os gases efluentes das torres por uma solução ácida, ou mesmo água. Por exemplo, a reação da amônia com ácido sulfúrico ou água possibilita a formação de sulfato de amônio ou aquamônia, produtos que podem ser utilizados como fertilizante. 


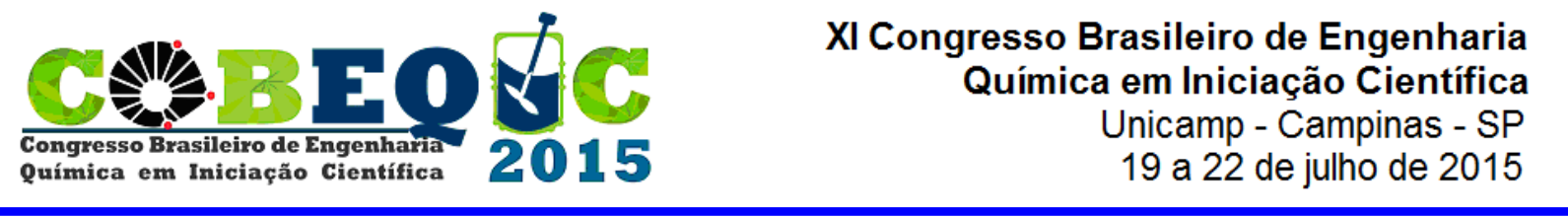

Os gases efluentes das torres, descontaminados, poderão ser liberados para a atmosfera, ou ainda serem queimados para evitar um possível lançamento de metano ou gás sulfídrico.

Neste contexto, o tratamento por air stripping de lixiviados de aterro industrial, efluentes de curtume e de outros processos industriais destaca-se como a principal aplicabilidade do método. O lixiviado é caracterizado pela variabilidade na composição química, alta toxidade aos ecossistemas e elevada geração, que é impulsionada pelo crescimento industrial, populacional e pelos padrões de consumo.

O processo de air stripping envolve a transferência de substâncias voláteis presentes na fase líquida (água residuária) para a fase gasosa (gás de arraste) (Kawamura, 2000). A eficiência da remoção está diretamente ligada à solubilidade do contaminante nas fases líquida e gasosa, à temperatura do meio, à vazão do gás de extração e à área de contato entre as duas fases (Metcalf; Eddy, 2003). Além disso, a concentração de nitrogênio amoniacal da água residuária e a configuração do reator são fatores com significativa influência sobre a eficiência do processo (Cheung et al., 1997).

A liberação da amônia volatilizada para a atmosfera representa uma das principais limitações do emprego desta tecnologia e uma importante fonte de preocupação. A emissão deve ser evitada, já que a solução da poluição dos corpos hídricos não deve resultar em uma nova problemática: a poluição atmosférica, que, em geral, apresenta maior gravidade e dificuldade de controle.

\section{OBJETIVOS}

Estudar a técnica de processo de air stripping aplicado ao tratamento de lixiviado de aterro de resíduos de curtume. Este trabalho busca verificar a eficiência de remoção de amônia pela torre de arraste através da técnica de air stripping, bem como determinar as condições operacionais que otimizem a remoção do nitrogênio amoniacal.

\section{METODOLOGIA}

Os procedimentos metodológicos utilizados na presente pesquisa foram definidos utilizando-se de uma revisão da literatura referente às técnicas de tratamento de lixiviado por stripping. Decidiu-se adotar o método da coluna de arraste, realizando-se um estudo preliminar com solução sintética 1000 ppm de amônia e, a partir deste, o desenvolvimento do estudo com o efluente propriamente dito. A utilização do estudo preliminar fez-se necessária para a determinação das condições operacionais relevantes do sistema e desta forma para a avaliação da vazão de recirculação, vazão de ar, volume a ser tratado e tempo por batelada necessários para que fossem obtidos níveis elevados de redução da concentração de amônia, assim programando essas variáveis para os ensaios com lixiviado.

\subsection{Colunas de aeração: construção e operação}

A coluna de aeração em escala de bancada foi utilizada em ambas as Etapas desta pesquisa. Os ensaios foram conduzidos em escala de bancada piloto e em regime batelada. As amostras de lixiviado foram submetidas ao processo de arraste utilizando 01 (uma) coluna de 


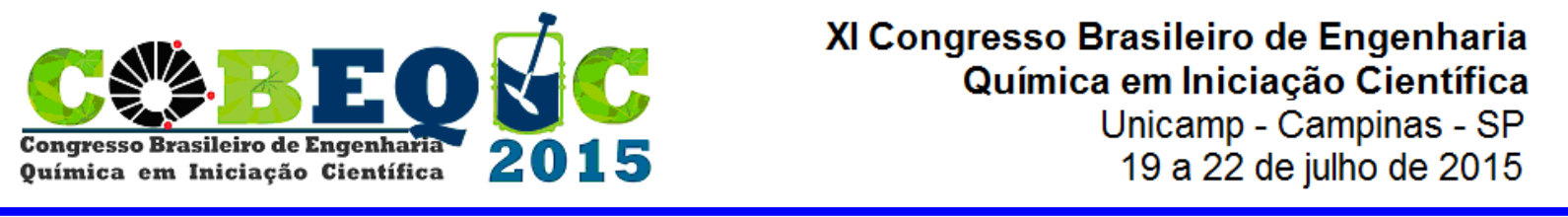

acrílico, com $70 \mathrm{~cm}$ de altura e $5 \mathrm{~cm}$ de diâmetro interno. O sistema de aeração foi composto por um compressor de geladeira, $1 / 3 \mathrm{CV}$, além de 01 (um) rotâmetro, marca OMEL, que realiza controle da vazão de ar. O rotâmetro 1 atua na faixa de 1 a $10 \mathrm{NL} \cdot \mathrm{min}^{-1}$ e as microbolhas necessárias para o arraste foram geradas por difusor espiral, comumente utilizado em aquários.

\subsection{Operação do Sistema Stripping}

A torre de stripping foi operada em regime de batelada, em contracorrente e teve tempo de ciclo (TC) de 24 horas, sendo realizada coleta de amostra com 24 horas de tratamento para verificação do desempenho do sistema. No interior da torre de stripping, o fluxo de ar teve sentido ascendente e o fluxo da solução sintética sentido descendente.

Conforme o ar entrava em contato com o líquido, a amônia em sua forma livre $\left(\mathrm{NH}_{3}\right)$ era arrastada para fora da torre de stripping juntamente com o ar, a partir da saída na região superior da torre. Em cada batelada, a solução sintética (ensaios da etapa 1) e depois na etapa 2 (ensaios com lixiviado), foram armazenados no tanque e recirculados utilizando a bomba de recirculação de marca Voges, $60 \mathrm{~Hz}$, até a parte superior da torre de stripping o qual operou com as vazões de 350, 175, 80 e 15 mL. $\mathrm{min}^{-1}$. Uma esquematização do sistema é encontrada na figura 1.

Figura 1 - Sistema de Air Stripping

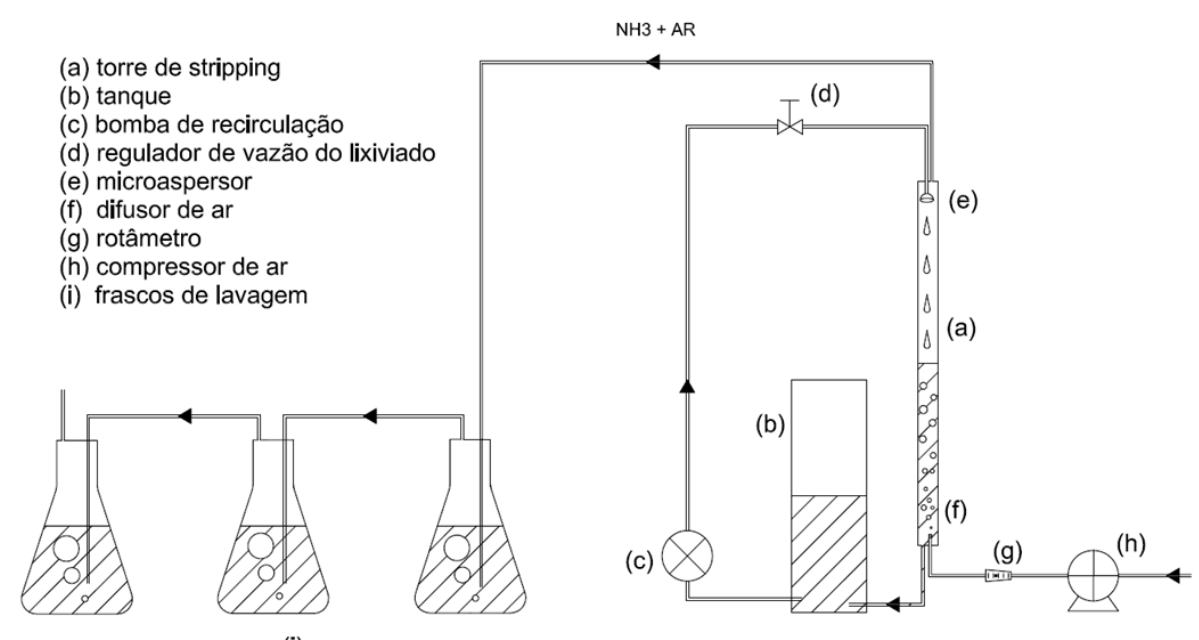

(i)

Em relação às vazões de ar enviada pelo compressor de 1/3, de marca TW 140, $60 \mathrm{~Hz}$, 400 psi de pressão, optou-se pela investigação na faixa máxima de $10,0 \mathrm{NL} \cdot \mathrm{min}^{-1}$. O fator vazão de ar (Qar) foi determinado com base em experimentos realizados por Santos (2009), nos quais, para testes realizados com vazões de ar de 2, 5 e 10 NL.min ${ }^{-1}$, foram verificadas diferenças significativas no desempenho do processo.

Com relação ao recolhimento de amônia, o aspecto visual da solução absorvente contida nos frascos era alterado, na medida em que ocorria neutralização de amônia. $\mathrm{O}$ 


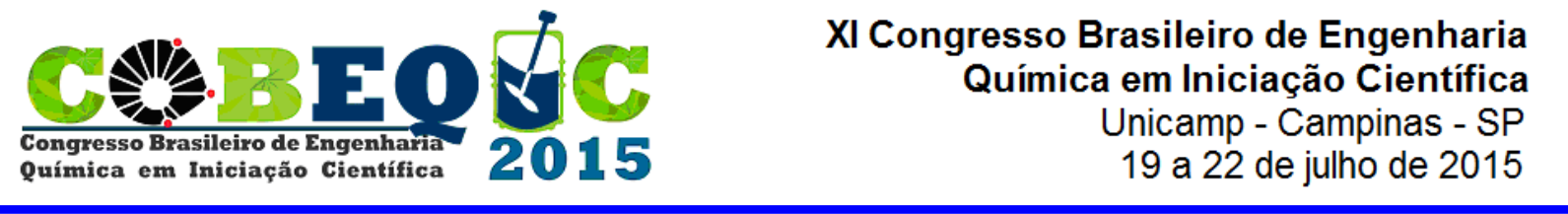

indicador fenolftaleína tornou muito mais prática à operação do sistema e, conforme havia mudança de cor em todos os frascos, o compressor era desligado para que houvesse substituição da solução dos frascos lavadores. Os frascos lavadores eram preenchidos com $500 \mathrm{~mL}$ de solução de ácido sulfúrico $0,4 \mathrm{~mol} / \mathrm{L}$. Uma alternativa para minimizar a perda de amônia foi o uso do indicador fenolftaleína, tanto na solução de ácido sulfúrico $0,4 \mathrm{~mol} / \mathrm{L}$. Esse indicador torna rosa a cor das soluções quando o $\mathrm{pH}$ é básico e, portanto, seu uso facilita a observação da ocorrência de neutralização da amônia nos frascos lavadores.

\section{RESULTADOS E DISCUSSÃO}

A partir dos resultados obtidos (Tabela 1), diversas possibilidades foram estudadas para o aprimoramento do sistema.

Tabela 1 - Ensaios preliminares

\begin{tabular}{cllll} 
Ensaio & $\begin{array}{l}\text { Valor } \\
\text { médio - } \\
\text { titulação } \\
\text { inicial } \\
\text { (mL) }\end{array}$ & $\begin{array}{l}\text { Valor } \\
\text { médio - } \\
\text { titulação } \\
\text { final }(\mathbf{m L})\end{array}$ & $\begin{array}{l}\text { Remoção } \\
(\%)\end{array}$ & $\begin{array}{l}\text { Desvio } \\
\text { padrão }\end{array}$ \\
\hline 1 & 11 & 2,5 & 78 & \\
2 & 12,3 & 2,9 & 76 & 2,3 \\
3 & 11,3 & 2,8 & 75 & 2,1 \\
4 & 14,5 & 4,1 & 72 & 2,4 \\
5 & 11,3 & 2,1 & 81 & 0 \\
6 & 11,4 & 1,4 & 88 & 0 \\
7 & 11,2 & 6,3 & 44 & 2,8 \\
8 & 10,5 & 4,5 & 57 & 2,6
\end{tabular}

Com relação ao lixiviado que foi trabalhado, a Tabela 2 mostra a sua caracterização. Os valores obtidos nas análises representam um efluente com grande carga orgânica e altos teores de nitrogênio amoniacal, com relação a outros efluentes de mesma origem.

Tabela 2 - Caracterização do Lixiviado

\begin{tabular}{l|cc}
\multicolumn{1}{c}{ PARÂMETRO } & UNIDADE & RESULTADOS \\
\hline OD & $\mathrm{mg} / \mathrm{L} \mathrm{O}_{2}$ & 0,6 \\
TEMPERATURA & ${ }^{\circ} \mathrm{C}$ & 15 \\
PH & - & 6,9 \\
DBO & $\mathrm{mg} \mathrm{DBO} / \mathrm{L}$ & 190.000 \\
DQO & $\mathrm{mg} / \mathrm{L} \mathrm{O}_{2}$ & $268.540,0$ \\
NITROGÊNIO & & \\
AMONIACAL & $\mathrm{mg} / \mathrm{L} \mathrm{NH}_{3}-\mathrm{N}$ & 27000,00 \\
NITRATO & $\mathrm{mg} / \mathrm{L} \mathrm{NO}_{3}-\mathrm{N}$ & 90,75 \\
NITRITO & $\mu \mathrm{g} / \mathrm{L}$ & $1.349,2$
\end{tabular}


O monitoramento é importante, pois informa a qualidade do lixiviado que está entrando no sistema de tratamento. Através dos parâmetros físico-químicos e biológicos verifica-se que o lixiviado é um líquido que apresenta alta heterogeneidade e variabilidade.

A partir da condição ótima de operação encontrada, realizaram-se ensaios (em andamento) utilizando lixiviado oriundo de aterro de resíduos de curtume. Portanto, os resultados e discussões são parciais. Como a pesquisa está em andamento, outros parâmetros serão analisados e discutidos posteriormente.

Diante desse contexto, durante o processo de tratamento do lixiviado, a eficiência total durante as 24 horas de ciclo de operação foi de $43 \%$, utilizando vazão de ar e recirculação de 5 NL. $\mathrm{min}^{-1}$ e $80 \mathrm{~mL} \cdot \mathrm{min}^{-1}$ respectivamente. De acordo com Caetano (2009), o aumento da vazão de recirculação de lixiviado gera menor remoção de nitrogênio; essa hipótese foi testada nos ensaios preliminares e deve ser aplicada nos ensaios posteriores com lixiviado. Salienta-se que o lixiviado passou por alcalinização, iniciando o ensaio com $\mathrm{pH}$ 11. Além disso, tal amostra apresenta uma concentração alta de nitrogênio amoniacal, cerca de $27000,00 \mathrm{mg} / \mathrm{L} \mathrm{NH} \mathrm{NH}_{3} \mathrm{~N}$, fato de grande relevância e ineditismo com relação às pesquisas consultadas. Quan (2009), obteve uma remoção de 85\% da amônia utilizando processo de air stripping com pH maior que 11. Segundo Giordano (2003) e Moura (2008), o pH ótimo para o processo de arraste é aproximadamente de 10,0 a 10,5. O aumento do $\mathrm{pH}$ para 12 promoveu uma eficiência de remoção de $50 \%$, porém não foi significativa quando comparada ao consumo de alcalinizante.

Nos experimentos cujas amostras não foram alcalinizadas, a formação de espuma pode estar relacionada às concentrações relativamente elevadas de surfactantes presentes no lixiviado, que segundo Giordano et al. (2002), são oriundas do descarte de embalagens de detergentes domésticos no aterro. Nos experimentos cujas amostras sofreram alcalinização, a formação de espuma pode estar relacionada às concentrações de surfactantes e possivelmente à reação de saponificação entre óleos e graxas, também presentes no lixiviado, com o hidróxido de sódio $(\mathrm{NaOH})$, resultando em uma maior formação de espuma. Dessa forma, pretende-se utilizar hidróxido de cálcio ou $\mathrm{CaO}$ virgem, nos próximos ensaios. Calli et al. (2005) comentaram que a formação de espuma pela utilização de $\mathrm{NaOH}$ foi reduzida substituindo-se esse composto por $\mathrm{Ca}(\mathrm{OH})_{2}$ para ajustar o $\mathrm{pH}$.

Ferraz (2010) também avaliou a recuperação da amônia liberada no processo de air stripping e obteve eficiência de até $80 \%$ com lixiviado de até $3000 \mathrm{mg} / \mathrm{L} \mathrm{NH}_{3}-\mathrm{N}$. A eficiência obtida no arraste de amônia foi de até $99 \%$, sendo que a alcalinização prévia do lixiviado foi considerada fundamental na redução do tempo necessário para que a remoção de amônia atingisse o nível esperado de $20 \mathrm{mg} / \mathrm{L}$. Calli et al. (2005), realizou um estudo da mesma escala, que nesta pesquisa, do aterro Komurcuoda (Istambul) usando stripping durante 12 horas. Obteve-se remoção de $94 \%$ de remoção de $\mathrm{NH}_{3}-\mathrm{N}$ com uma concentração inicial de $3260 \mathrm{mg} / \mathrm{L}$.

É consenso da literatura que maior vazão de ar gera mais remoção. Assim, este parâmetro foi mantido no máximo permitido pelo sistema.

\section{CONSIDERAÇÕES FINAIS}


Apesar dos resultados satisfatórios amplamente descritos na literatura, o processo de air stripping apresenta diversas desvantagens e limitações, que devem ser consideradas na escolha desta tecnologia de tratamento de águas residuárias e/ou no projeto das unidades de tratamento.

\section{REFERÊNCIAS}

CAETANO, M. O. Aplicação do reator de chicanas no tratamento de lixiviados de aterros sanitários de resíduos sólidos urbanos para remoção de nitrogênio amoniacal por stripping. Dissertação de mestrado. Programa de Pós-Graduação em Engenharia Civil. Universidade do Vale do Rio dos Sinos, 2009.

CALLI, B.; MERTOGLU, B.; INANC, B. Landfill leachate management in Istanbul: applications and alternatives. Chemosphere. v. 59, 2005.

CHEUNG, Kwai C.; CHU, Lee M.; WONG, Ming H. Ammonia stripping as a pretreatment for landfill leachate. Water, Air and Soil Pollution, v. 94, n. 1-2, p. 209-211, 1997.

FERRAZ, F. M. Recuperação da amônia liberada no processo de air stripping aplicado ao tratamento de lixiviado de aterros sanitários. Dissertação de Mestrado. Programa de PósGraduação Área de concentração em Engenharia Hidráulica e Saneamento. Escola de Engenharia de São Carlos da Universidade de São Paulo, 2010.

GIORDANO, G.; FERREIRA, J. A.; PIRES, J. C. A.; RITTER, E.; CAMPOS, J. C.; ROSSO, T. C. A. Tratamento de chorume do aterro metropolitano de Gramacho - Rio de Janeiro Brasil. In: Congresso Interamericano de Ingeniería Sanitaria y Ambiental. Cancún - México. 2002.

GIORDANO, G. Análise e formulação de processos para tratamento dos chorumes gerados em aterros de resíduos sólidos urbanos. 2003. 257 f. (Tese de Doutorado) Pontifícia Universidade Católica do Rio de Janeiro. Departamento de Ciências dos Materiais e Metalurgia, 2003.

KAWAMURA, Susumu. Integrated design and operation of water treatment facilities. 2. ed. New York: John Wiley \& Sons, 2000. 691 p.

METCALF \& EDDY, INC. Wastewater engineering: treatment and reuse. $4^{\mathrm{a}} \mathrm{ed}$. International Edition. Revisada por TCHOBANOGLOUS, G.; BURTON, F.L.; STENSEL, H.D. New York: McGraw-Hill, 2003. 1819 p. (McGraw-Hill series in civil and environmental engineering).

MOURA, D. A. G. Remoção de Amônia por Arraste com Ar de Lixiviados de Aterros Sanitários. 131 f. Dissertação de Mestrado. Escola de Química, Universidade Federal do Rio de Janeiro, Rio de Janeiro, 2008.

QUAN, X.; WANG, F., ZHAO, Q.; ZHAO, T., XIANG, J. Air stripping of ammonia in a water-sparged aerocyclone reactor. Journal of Hazardous Materials, v. 170, p 983-988, (2009). 
SANTOS, A. F. de M. S. Tratamento anaeróbio de chorume em conjunto com esgoto sanitário. 2009. 166 f. Tese de Doutorado - Programa de Pós-Graduação em Engenharia Civil, Universidade Federal de Pernambuco. CTG. Recife, 2009. 